International Journal of English Literature and Social Sciences
Vol-7, Issue-1; Jan-Feb, 2022
Journal Home Page Available: https://ijels.com/
Journal DOI: $10.22161 /$ ijels

Peer-Reviewed Journal

\title{
The Contribution of Leg Length, Leg Muscle Strength, Arm Span and Maximum Oxygen Volume to 100-Meter Crawl Swimming Achievement
}

\author{
(Correlational Study on Intermediate Level of Female Athletes Pandhowo Swimming \\ Club)
}

Fariz Muhammad Ihsan, Sugiyanto, Slamet Riyadi

Department of Sports Science, Postgraduate Program, Sebelas Maret University (UNS), Indonesia. Jalan Ir. Sutami No. 36A, Jebres, Kota Surakarta, Central Java, post code:57126, Indonesia. Phone: (+62)271-646994, Fax: (+62)271-636268, Email:Ihsanfariz3452@gmail.com

Received: 15 Dec 2021; Received in revised form: 24 Jan 2022; Accepted: 05 Feb 2022; Available online: 12 Feb 2022 (C)2022 The Author(s). Published by Infogain Publication. This is an open access article under the CC BY license (https://creativecommons.org/licenses/by/4.0/).

\begin{abstract}
This study aimed to analyze the contribution of leg length, leg muscle strength, arm span, and maximum oxygen volume of athletes to the performance of 100-meter crawl style swmming, and how significant the contributions were. This study employs a descriptive and correlational research method. Specifically, this research focused on 40 Pandhowo Swimming Club female athletes with an age range of 12-13 years old. In this study, there are four independent variables: leg length, leg muscle strength, arm span, and maximum oxygen volume. While the performance of the 100-meter crawl style swimming is used as the dependent variable. This study collected data through tests and measurements of each variables, and the analysis is done using correlation technique, which tests normality, linearity, and hypotheses Results indicated that leg length, leg muscle strength, arm span, and maximal oxygen volume contributed significantly to the performance of the 100-meter crawl style swimming. The effective and relative contribution of each variable is as follows: leg length has an effective contribution of $15 \%$ and a relative contribution of $20 \%$, leg muscle strength has an effective contribution of $20 \%$ and a relative contribution of $30 \%$, arm span has an effective contribution of $6 \%$ and a relative contribution of $9 \%$, and maximal oxygen volume has an effective contribution of $25 \%$ and a relative contribution of $38 \%$.
\end{abstract}

Keywords-Crawl, contribution, intermediate.

\section{INTRODUCTION}

Sport basically has a very important and strategic role for efforts to form and improve the quality of human resources for further development. Sports are considered important in order to support the formation of character and personality, discipline, high sportsmanship, as well as increasing achievements that can generate a sense of pride and national unity. In another side sports is having important role, namely to form a complete human being physically and mentally.
Achievement in sports is a complex thing because of many factors that influence it. Coaching in swimming is one of the efforts to increase maximum achievement through coaching at a young age. Swimming is a sport having good demand by many people, both among children and adults. Swimming was introduced to the Olympics in 1912. People usually swim using various styles, such as the crawl style. This style is very easy to do by all circles, both beginners / children and adults. The basics of swimming are vary, including the introduction of water, head movements, hand movements, foot movements to how to take a breath. 
Strength is an important element in supporting movement skills. Strength as the maximum active power can be done by a group of muscles in one effort. Strength also functions as the amount of muscle effort that contracts to get the ability with maximum tension. Leg muscle strength is a basic component to provide impetus for movement to be effective and efficient. Most of the thrust in the swimmer is generated by the movement of the legs

In crawl swimming, the effort made to get a forward thrust is also generated by the stroke of the arm. Arm stroke in crawl style swimming serves as a puller and pusher. The number of arm strokes varies from one athlete to another. This is due to differences in body size such as arm size, arm length and arm span. The athletes who have long arm spans with athletes who have short arm spans can produce different forces in providing propulsion in swimming. Because the reach of the arm at the time of pulling and pushing is what makes the difference in generating thrust.

Maximum oxygen volume is one of the components of physical condition that is important in achieving achievement. Athletes who have a good maximum oxygen volume will be able to carry out strenuous activities for long periods of time without experiencing fatigue. According to Sukadiyanto (2010: 60) a common man, athlete or coach who wants to increase endurance or endurance must know very well since what needs to be improved is the working ability of the cardiovascular system.

Physical ability is an important element in reaching the achievement in swimming. The contribution of physical condition to swimming sports achievement still needs to be studied in depth. Efforts to reach achievement in swimming sports needs to be concerned to the elements of physical conditions that affect the sport. In training, you must pay attention to the elements of leg length, arm span and maximum oxygen volume by providing the right exercise program.

In the swimming competition there are various numbers that are contested. One of them is the crawl style with a distance of 100 meters. Swimming in crawl style at a distance of 100 meters requires more physical components, even anthropometry of athletes with certain criteria is needed compared to numbers under 100 meters. Crawl style swimming is done with the body prone position. The basic techniques that must be mastered in crawl style swimming are gliding movements, leg movements, arm movements and breathing. From these movements, an athlete must be able to coordinate the

$$
\text { II. METHOD }
$$

movements of one to another movement as a whole. In that way an athlete will get an effective and efficient movement.

In swimming, aside from mastering the basic techniques of swimming, athletes must also have skills in swimming. In addition, every sport has a diverse composition of physical needs and also every member of the body in athletes has various important roles in achieving an achievement. Physical factors are one of the factors that can support the achievement of sports achievements. Mochamad Sajoto (1995: 11) states, "one of the aspects in reaching achievement in sports is the biological aspect which includes the structure and posture of the body, namely: (1) leg size and length, (2) large size, width and weight, (3 ) somatotype (body shape)".

Each of these components is of course interrelated in carrying out their business, the relation between one part and another is felt to be very necessary, such as leg length, leg muscle strength, arm span with a strong maximum oxygen volume. Each of these parts contributes to swimming performance, especially in the crawl style. The contribution can have a positive effect on swimming movements because by knowing the contribution of these parts an athlete can maximize the correct and appropriate movement so that it is more efficient in swimming. More or less mistakes can be avoided and minimized by practicing the right and good movements.

To be able to provide physical exercise appropriately and according to muscle development and the athlete's maximum oxygen volume, it can be arranged according to the variables on the achievement of swimming sports achievements. The role of leg length, leg muscle strength, arm span and maximum oxygen volume on the achievement of the 100 meter crawl style swimming sport can be seen through the contribution of each variable to achievement. Because the contribution of each variable is not known yet, it is necessary to conduct research first. The Pandhowo Sukoharjo, Klaten and Cilacap swimming clubs need attention. This is because in the club there is a gap in results and the achievement of the 100-meter crawl style swimming time. This gap is found in intermediate level female athletes aged 13-14 years. When a trial time/test was conducted for the 100-meter crawl style swimming, female athletes aged 13-14 years had very varied time differences, even though the training program given to athletes was an equal portion of the training program.

The method in this study is a descriptive method with correlational study techniques. Sugiyanto (1994:57) 
states, "Through a correlational study it can be known whether one variable is associated with another variable. Arikunto (1996) The relation between variables is determined by using a correlation coefficient calculated by statistical analysis techniques. This study will describe the relation and the magnitude of the contribution between leg length, arm span and maximum oxygen volume in the 100 meter crawl style swimming achievement. Sampling was done by purposive sampling technique. The sample in this study was set specifically for beginner level swimming athletes at the Pandhowo Swimming Club who could swim freestyle as many as 40 intermediate level female athletes aged 13-14 years.

The instruments used in this study were a test using a meter to measure leg length and arm span, a test using a leg dynamometer to measure leg muscle strength, and a 12-minute swimming test to measure maximum oxygen volume. The data that has been collected from each test instrument is then processed using SPSS by looking for normality, linearity test, partial correlation test of each independent variable $(\mathrm{X})$ to the dependent variable $(\mathrm{Y})$, and finally looking for regression analysis.

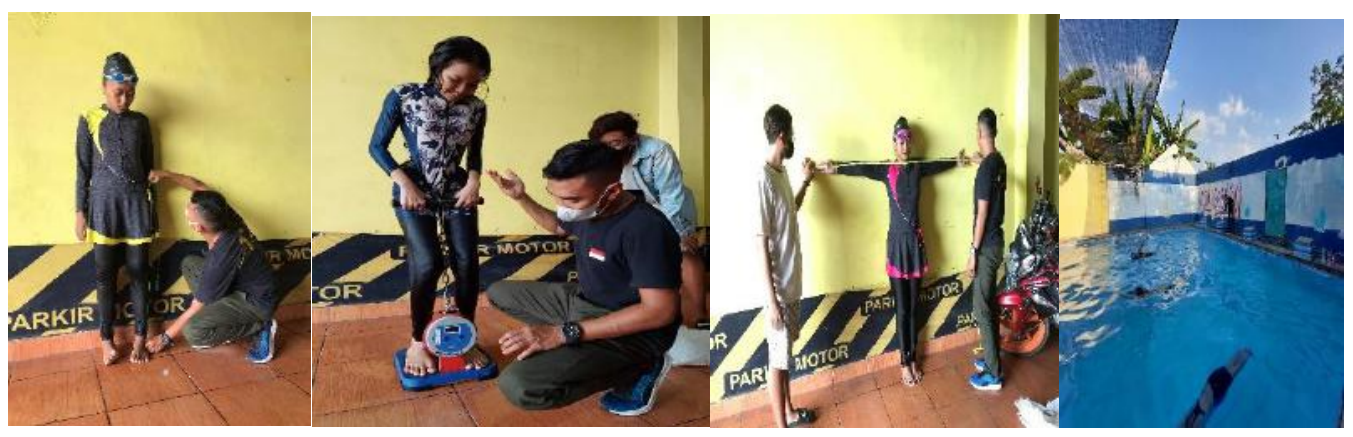

\section{RESULT}

a. The relation between the athlete's leg length and the achievement of the 100 meter crawl style swimming and how much it contributes.

Based on the results of two data analyzes that have been carried out on the athlete's leg length data on the achievement of the 100 meter crawl style swimming; the first analysis with product moment correlation analysis obtained a sig value of 0.00 . This value is smaller than the sig value at a significance level of 0.05 . Because the arithmetic value of $\mathrm{sig}<$ 0.05 , the correlation value between the variables $\mathrm{x}$ and $y$ is significant. The result of calculating the correlation coefficient shows a value of 0.649 . This means that the 100 meter crawl style swimming achievement variable is influenced by the element of leg length with a strong degree of relation. The second analysis using partial correlation analysis, partial correlation coefficient of leg length with swimming achievement of 100 meter crawl style controlling leg muscle strength, arm span and VO2max, obtained a partial correlation coefficient of 0.240 . With $\mathrm{df}=38$. It turns out that the calculated value of significance $=$ $0.152>$ sig value of 0.05 . This shows that there is no significant relation between leg length and the achievement of the 100 meter crawl style swimming at a certain level of leg muscle strength, arm span and VO2max. Then based on the results of calculating the effective contribution and relative contribution, the length of the legs gives a value of $15 \%$ and $23 \%$ for the achievement of the 100 meter crawl style swimming. The results of the two analyzes show different results, where between the results of single correlation and partial correlation there is a difference in significance level. This means that the length of the legs can affect the swimming performance of the 100 meter crawl style maximally when there is a single correlation. The opposite thing happened when the leg length affected the swimming performance of the 100 meter crawl style at a certain level of variable leg muscle strength, arm span and VO2max, there was still a relation but with a less degree of relation. Thus the hypothesis which states that there is a relation between leg length and the achievement of swimming in the 100-meter crawl style can be accepted as true.

b. The relation between the athlete's leg muscle strength and the achievement of the 100-meter crawl style swimming and how much it contributes.

Based on the results of two data analyzes that have been carried out on data on leg muscle strength with the achievement of swimming in the 100 meter crawl style, the first analysis with product moment correlation analysis obtained a sig value of 0.00 . The sig count value of 0.00 is smaller than the 0.05 significance. Because the value of sig count $<0.05$, the correlation value is significant. Then the result of calculating the correlation coefficient shows 0.676 . This means that the 100 meter crawl style swimming achievement variable is influenced by the element of leg muscle strength with the degree of relation being 
said to be strong. The second analysis with partial correlation analysis, the partial correlation coefficient of leg muscle strength with the achievement of swimming in the 100 meter crawl style controlling leg length, arm span and VO2max, obtained a partial correlation coefficient of 0.355 with $\mathrm{df}=38$. It turns out that the count sig $=0.031<0.05$. This shows that there is a significant relation between leg muscle strength and the achievement of swimming in the 100 meter crawl style at the level of leg length, arm span and a certain VO2max has a less degree of relation. Thus, the hypothesis which states that there is a relation between leg muscle strength and swimming achievement in the 100-meter crawl style can be accepted as true.

c. The relation between the athlete's arm span and the achievement of the 100-meter crawl style swimming and how much it contributes.

Based on the results of two data analyzes that have been carried out on the athlete's arm span data on the 100 meter crawl style swimming achievement; the first analysis with product moment correlation analysis obtained a sig value of 0.00 . This value is smaller than the sig value at a significance level of 0.05 . Because the arithmetic value of sig $<0.05$, the correlation value between the variables $\mathrm{x}$ and $\mathrm{y}$ is significant. The result of calculating the correlation coefficient shows a value of 0.670 . This means that the 100 meter crawl style swimming achievement variable is influenced by the arm span element with a strong degree of relation. The second analysis with partial correlation analysis, the partial correlation coefficient of arm span with the achievement of swimming 100 meter crawl style controlling leg muscle strength, leg length and VO2max, obtained a partial correlation coefficient of 0.081 . With $\mathrm{df}=38$. It turns out that the calculated value of significance $=$ $0.633>\operatorname{sig}$ value of 0.05 . This shows that there is no significant relation between arm span and the achievement of the 100 meter crawl style swimming at a certain level of leg muscle strength, leg length and VO2max. Then based on the results of calculating the effective contribution and relative contribution, the arm span gives a value of $6 \%$ and $9 \%$ on the achievement of the 100-meter crawl style swimming. The results of the two analyzes show different results, where between the results of single correlation and partial correlation there is a difference in significance level. This means that the arm span is able to maximally affect the 100 meter crawl style swimming performance when there is a single correlation. The opposite thing happened when arm span affected the
100 meter crawl style swimming performance at a certain level of leg muscle strength, leg length and VO2max variable, there was still a relation but with a very weak degree of relation. Thus, the hypothesis which states that there is a relation between arm span and the achievement of the 100-meter crawl style can be accepted as true.

d. The relation between the athlete's maximum oxygen volume and the achievement of the 100-meter crawl style swimming and how big is the contribution.

Based on the results of two data analyzes that have been carried out on the maximum oxygen volume data with the achievement of the 100 meter crawl style swimming, the first analysis with the product moment correlation analysis obtained a sig value of 0.00 . The sig count value of 0.00 is smaller than the 0.05 significance. Because the value of sig count $<0.05$, the correlation value is significant. Then the result of calculating the correlation coefficient shows 0.689. This means that the 100 meter crawl style swimming achievement variable is influenced by the element of maximum oxygen volume with the degree of relation being said to be strong. The second analysis with partial correlation analysis, the partial correlation coefficient of maximal oxygen volume with the achievement of 100 meter crawl style swimming controlling leg length, arm span and leg muscle strength, obtained a partial correlation coefficient of 0.406 with $\mathrm{df}=38$. It turns out that the count $\operatorname{sig}=0.013<0,05$. This shows that there is a significant relation between the maximum oxygen volume and the achievement of the 100 meter crawl style swimming at the level of leg length, arm span and certain leg muscle strength having a sufficient degree of relation. Thus the hypothesis which states that there is a relation between maximum oxygen volume and the achievement of the 100 meter crawl style can be accepted.

e. The relation between leg length, leg muscle strength, arm span and maximum oxygen volume of athletes with the achievement of swimming in the 100 meter crawl style and how big their contribution is.

Based on the results of the calculation of the correlation of leg length (X1), leg muscle strength (X2), arm span (X3) and maximum oxygen volume (X3) on the achievement of 100 meter crawl style swimming $(\mathrm{Y})$, the sig $\mathrm{F}$ change value is $0.00<0.05$. This shows that there is a simultaneous correlation or relation between leg length (X1), leg muscle strength (X2), arm span (X3) and maximum oxygen volume (X4) on the achievement of 100 meter crawl style 
swimming (Y). Meanwhile, based on the results of multiple correlation calculations, the $\mathrm{R}$ value is 0.812 . Therefore, it can be concluded that there is a very strong degree of categorical relation between leg length (X1), leg muscle strength (X2), arm span (X3) and maximum oxygen volume (X4) on the achievement of 100 meter crawl style swimming (Y).

\section{DISCUSSION}

Based on the results of descriptive analysis with a sample of 40 female swimmers in the intermediate category for the variable leg length, it was obtained an average of 85.68 with a standard deviation of 5.65 , the highest score of 100 and the lowest score of 75 . Description of the data for the variable leg muscle strength obtained an average an average of 73.87 with a standard deviation of 29.911, the highest score of 154 and the lowest score of 32. Description of the data for the arm span variable obtained an average of 151.04 with a standard deviation of 10,518, the highest score of 177 and the lowest score of 130. Description of the data for the volume variable maximum oxygen obtained an average of 626.87 with a standard deviation of 74,547 the highest score of 177 and the lowest score of 130. Description of the data for the 100 meter freestyle/crawl swimming ability variable obtained an average of 116.15 with a standard deviation of 27,544 the highest score 175 and the lowest score is 74 . The results of the descriptive analysis are decisive for testing the results of each ng variable

\section{CONCLUSION}

Based on the results of the research and the results of data analysis conducted, this study concludes that the components of physical condition and anthropometric components that have a relation and influence on the achievement of the 100 meter crawl style swimming and the existing variables are leg length, leg muscle strength, arm span and Vo2max. These variables were processed and analyzed by calculating the correlation coefficient of each predictor to the criteria and knowing the partial correlation and calculating the multiple correlation between the predictor and the criteria as well as the contribution of each predictor.

After being analyzed using product moment correlation analysis, partial correlation and regression analysis that has been carried out, the following conclusions can be obtained:

1. There is a significant relation between the length of the legs on the achievement of swimming in the 100 meter crawl style, with a correlation value of 0.649 .
These results indicate the relation between the variables is negative (-) or reversed. These results indicate that the greater the contribution of limb length, the less time it takes to achieve the 100 meter crawl style swimming achievement.

2. There is a significant relation between leg muscle strength and the achievement of swimming in the 100 meter crawl style, with a correlation value of 0.676 . These results indicate the relation between the variables is negative (-) or reversed. These results indicate that the greater the contribution of leg muscle strength, the less time it takes to achieve the 100 meter crawl style swimming achievement.

3. There is a significant relation between arm span on the achievement of the 100 meter crawl style swimming, with a correlation value of 0.670 . These results indicate the relation between the variables is negative (-) or reversed. These results indicate that the greater the contribution of the arm span, the less time it takes to achieve the 100 meter crawl style swimming achievement.

4. There is a significant relation between the maximum oxygen volume and the achievement of the 100 meter crawl style swimming, with a correlation value of 0.689 . These results indicate the relation between the variables is negative (-) or reversed. These results indicate that the greater the contribution of the maximum oxygen volume, the less time it takes to achieve the 100 meter crawl style swimming achievement.

5. There is a significant relation between leg length, leg muscle strength, arm span and the achievement of swimming in the 100 meter crawl style, with an $\mathrm{R}$ value of 0.812 . These results indicate that there is a very strong degree of relation between leg length (X1), leg muscle strength (X2), arm span (X3) and maximum oxygen volume $(\mathrm{X} 4)$ on the achievement of the 100 meter crawl style swimming (Y).

6. From the data analysis that has been done, the relative contribution of each independent variable to the dependent variable is obtained as follows;

a. Leg length contributes $23 \%$ relative.

b. Leg muscle strength contributes a relative $30 \%$.

c. Arm span provides a relative contribution of $9 \%$.

d. Maximum oxygen volume provides a relative contribution of $38 \%$

While the effective contribution of each independent variable to the dependent variable is as follows:

a. Leg length provides an effective contribution of $15 \%$.

b. Leg muscle strength provides an effective contribution of $20 \%$ 
c. Arm span provides an effective contribution of $6.4 \%$.

d. The maximum oxygen volume provides an effective contribution of $25 \%$. So that the total effective contribution of the four variables to the 100 meter crawl style swimming achievement is $66 \%$.

This shows that the contribution of maximal oxygen volume is the variable that has the most dominant contribution, followed by the variable leg muscle strength, leg length and the smallest contribution is the arm span variable. Meanwhile, the remaining $34 \%$ is a contribution from other factors other than those represented by the independent variables. The predictions from the researchers of these other factors could be influenced by the factor of training or other physical condition factors that also support the achievement of the 100 meter crawl style swimming

\section{REFERENCES}

[1] Arikunto, Suharsimi. 1996. Prosedur Penelitian. Jakarta: PT Rineka Cipta.

[2] Perpustakaan.id. (2019, 23 Juli). Teknik Dasar Renang Gaya Bebas Beserta Gambarnya Lengkap. Diakses pada 10 Februari 2020, dari https://perpustakaan.id/renang-gayabebas/

[3] Sajoto, M. 1988. Pembinaan Kondisi Fisik dalam Olahraga. Jakarta: Departemen Pendidikan dan Kebudayaan Direktorat Jenderal Pendidikan Tinggi Proyek Pengadaan Buku pada Lembaga Pengembangan Tenaga Pendidikan.

[4] .1995. Pengembangan dan Pembinaan Kekuatan Kondisi Fisik dalam Olahraga. Semarang: Dahara Press.

[5] Sukadiyanto. 2010. Pengantar teori dan meto-dologi melatih fisik . Yogyakarta: Uni-versitas Negeri Yogyakarta.

[6] Sugiyanto.1994. Metodologi Penelitian Pendidikan. Surakarta: UNS Press.

[7] _.1996. Belajar Gerak I. Surakarta: UNS Press.

[8] Sugiyanto, FX., dan Agus Supriyanto. 2004. Mekanika Renang, Start dan Pembalikan. Yogyakarta: FIK UNY.

[9] Sugiyono. 2007. Metode Penelitian Kuantitatif Kualitatif dan $R \& D$. Bandung: Alfabeta.

[10] 2008. Statistik Untuk Penelitian. Bandung: Alfabeta.

[11]_2013. Metode Penelitian Pendidikan Pendekatan Kuantitatif, Kualitatif, dan R\&D. Bandung: Alfabeta.

[12] _.2014. Memahami Penelitian Kualitatif. Bandung: Alfabeta. 